\section{MODERNIDAD Y CAMBIO SOCIAL: UNA PERSPECTIVA INTEGRADORA, O EL MÁS ACÁ DE LOS ESTUDIOS DE GÉNERO}

\author{
Lourdes Flamarique \\ Universidad de Navarra \\ Iflamarique@unav.es
}

\section{MODERNITY AND SOCIAL CHANGE. AN INTEGRATIVE PERSPECTIVE OR WHAT WOULD BE THE WAY BELOW OF GENDER STUDIES}

Copyright: (c) 2016 CSIC. Este es un artículo de acceso abierto distribuido bajo los términos de la licencia Creative Commons Attribution (CC BY) España 3.0.
RESUMEN: En este artículo se abordan algunos cambios en los modos de vida de las mujeres, con la pretensión de que su carácter "moderno" los inscribe en el ámbito de la cultura objetiva, esto es, alcanzan a toda la condición humana y permiten interpretar y comprender mejor las transformaciones sufridas por todos los seres humanos. Tras una primera parte en la que se considera la co-relación de modernidad y cambio socio-cultural, la exposición fija su atención en algunos de los ejes temático-conceptuales que caracterizan el actual estilo de vida de las mujeres (trabajo, familia y amor romántico) y, consecuentemente, de toda la sociedad.

PALABRAS CLAVE: Modernidad; cambio social; estilos de vida; femenino; trabajo; familia; amor romántico.
ABSTRACT: This article analyzes some changes in the lifestyles of women, with the claim that their "modern" character falls within the scope of the objective culture, i.e., they encompass the entire human condition, enabling us to interpret and understand better the transformations of all human beings. After the first part, which considers the co-relation of modernity and socio-cultural changes, the argumentation focuses on some of the thematic-conceptual themes (work, family and romantic love) that characterize the current lifestyle of women and, consequently, society as a whole.

KEYWORDS: Modernity; social change; lifestyles; female; work; family; romantic love. 
Ha pasado ya más de un siglo desde que Georg Simmel afirmara que el varón no se concibe a sí mismo como sexuado, sino que identifica lo masculino con lo propio del ser humano, y se convierte en representante de la humanidad en general, mientras que lo femenino es visto siempre como algo característico, particular (1938, p. 90). La razón de esta diferencia radicaría en que "la mujer vive en la identidad más profunda de su ser y de su condición de mujer, en el carácter absoluto de una condición sexual determinada en sí misma" (Simmel, 2003, p. 468) ${ }^{1}$. Si en un caso la parte llega a estar por el todo, en el otro su totalidad es siempre parcial. Esta parcialidad insuperable sobrevive al menos en lo que respecta a la relevancia de los estudios dedicados a la mujer: despiertan interés en un público mayoritariamente femenino, y se acepta que lo que está en juego afecta principalmente a esa mitad de la población, por lo que sus tesis y sus conclusiones no son extrapolables al ser humano en general. Si el enfoque de estos estudios es político o sociológico, suele coincidir que sus autores son mayoritariamente autoras (es mi caso y tal vez también el del resto de los coautores de este número). Como ha señalado, entre otros, la socióloga A. R. Hochschild, mayoritariamente se considera la realidad social desde la perspectiva masculina, y solo respecto de fenómenos particulares se ofrece el punto de vista femenino (1975, p. 280).

La dialéctica particular-universal, parte-todo, no es inocua desde el punto de vista político-cultural. No voy a examinar este modo de proceder, aunque sí plantear brevemente a qué se debe que, cuando se considera la perspectiva masculina, esta se pretenda universalizable, referente de lo humano; esto es, que los valores masculinos se identifiquen con los valores del ser humano en general. Una respuesta obvia sería afirmar que lo que tiene que ver con el varón entra a formar parte del imaginario social sin restricciones, mientras que lo que tiene que ver con la mujer limitadamente, y a menudo como un subcampo de las ideas y significados. ¿Es esto el efecto, sin más, del ancestral predominio cultural, social y científico de lo masculino sobre la cultura femenina? Es decir, ¿es el resultado de un desequilibrio de poder? Simmel atribuía esta desigualdad al desfase entre la forma de ser femenina y la cultura objetiva (Beriain, 1989). Desfase que, entre otros motivos, responde a que "percibimos la mujer no tanto bajo la especie del cambio como bajo la especie de la permanencia" (Simmel, 1938, p. 47). Se trata de un diferencial, el del cambio, que a lo largo del siglo XX ha adoptado un significado y una función característica. Por ello, el diagnóstico de Simmel señala también una línea divisoria, un antes y un después, como trataré de argumentar a lo largo de estas páginas.

La tesis de partida de este trabajo es que la correlación entre modernidad y cambio cultural o social, es decir, la aplicación de aquella en términos de transformación de todas las esferas del vivir humano, desdibuja algunas distinciones a propósito de lo femenino y masculino, más propias de una cultura en la que las necesidades de crecimiento, la subsistencia económica y la inseguridad política dominan sobre el resto. El proyecto moderno de transformación social es universal en su definición y ejecución. Es decir, los cambios incoados alteran tanto el modo de ser femenino como el masculino.

En las páginas siguientes se abordan algunos cambios en los modos de vida de las mujeres, con la pretensión de que su carácter "moderno" los inscribe en el ámbito de la cultura objetiva, esto es, alcanzan a toda la condición humana y permiten interpretar y comprender mejor las transformaciones sufridas por todos los sujetos. No se trata de examinar realidades, figuras de la cultura que lleven el sello femenino, sino de mostrar cómo el modo en que las mujeres las encarnan, las configuran, revela la índole entera de esas realidades, por lo que desde ellas surge una correlación universal humana para la vida moderna. En ciertas expresiones de la vida y concreciones de lo humano generalizadas en las sociedades desarrolladas, en las que las mujeres tienen un papel protagónico, lo que se ofrece no es la resolución de un problema o la satisfacción de una necesidad de una parte de la humanidad, sino algo potencialmente significativo para el conjunto. Es decir, al examinar los modos de relacionarse con la realidad y de interpretarse de las mujeres en el contexto de las sociedades modernas, se pretende que no está en juego algo peculiar o parcial sino que estamos ante un punto de referencia para el conjunto de la sociedad y un factor determinante de los modos masculinos. En ese sentido se propone la modernidad como un "más acá" de los estudios de género.

\section{LA CUESTIÓN MODERNA, UNA PERSPECTIVA INTEGRADORA}

Una constante del pensamiento contemporáneo es la reflexión en torno a la idea de modernidad. La importancia del análisis de la modernidad -o de su crisis- se sigue en gran medida del hecho de que constituye la puesta de largo, la presentación pública de los implícitos filosóficos que la llustración y, con ella, la misma filosofía moderna ocultaban tras el 
ideal de un conocimiento y acción racional. El desencantamiento del mundo traslada el discurso filosófico del punto de gravedad de la teoría del conocimiento y la filosofía de la conciencia a los problemas de una teoría de la cultura y de la historia. Lo moderno es visto como un problema que convoca a todas las instancias intelectuales, y genera una literatura específica hasta nuestros días.

La contraposición de una cultura objetiva, dominada en gran medida por el ideal de racionalización, y una cultura subjetiva, impulsada por aspiraciones y demandas que giran todas ellas en torno al ideal de libertad y realización individual, anuncia ya en los albores del siglo XX la deriva de revisiones y crisis antes mencionadas. Cabría reducir estas tensiones a una sola; la que se da entre el ideal de igualdad y el deseo de diferenciarse. Como es notorio, de esta tensión se alimentan las continuas transformaciones operadas en los últimos siglos en las sociedades occidentales.

Cabe hablar de modernidad en muchos sentidos. Lo que el término parece expresar de modo insistente es la conciencia de época que se pone en relación con otro tiempo para verse a sí misma como resultado de la transición de lo viejo a lo nuevo. Con especial fuerza se hace presente la modernidad social y cultural. Si la cultura es una síntesis de las formas objetivas (conocimientos, arte, socialidad, costumbres y prácticas morales, instituciones y estructuras configuradoras del orden socio-económico, etc.) que los individuos asimilan y encarnan renovándolas (Simmel, 1938, p. 7), a lo largo del siglo XX el denominador común de todas ellas ha sido su "modernidad". Y esto es así con todas las paradojas y conflictos que justifican hablar del proyecto moderno en términos de una dialéctica (Horkheimer, Adorno). Habermas define lo moderno como aquello que está presente en la expresión objetiva de una contemporaneidad (Aktualität) espontánea y autorrenovadora del espíritu de los tiempos. Es indicado por aquello que es nuevo, aquello que será sobrepasado y devaluado por la novedad del siguiente estilo. Modernidad implica, por tanto, la transformación de la conciencia del tiempo; se orienta hacia un futuro todavía no realizado. Impera la lógica del cambio y la sobrevaloración de lo transitorio, lo fugaz, lo efímero; en la celebración de lo dinámico está también expresado el deseo de un presente sin mancha, todavía intacto (Habermas, 1988, p. 89).

Como he apuntado ya, si hay dos categorías que aparecen entreveradas en la teoría de la cultura, estas son cambio y modernidad; están incorporadas al vocabulario común de tal manera que pocas veces advertimos el peso específico que tienen en la configuración de nuestra experiencia social, ni su "juventud" dentro de historia de la cultura. Ciertamente hablamos de historia porque se producen cambios que son esenciales en la vida social, política, moral, etc. Pero hasta hace poco más de tres siglos, la categoría del cambio no era por sí sola significativa, tan solo una categoría instrumental que designa el paso de una época a otra, de una cultura a otra. Solo la modernidad ha dotado de valor en sí mismo al cambio hasta convertirlo en ley interna de la vida social moderna. Con otras palabras, el cambio social y cultural no es un fenómeno nuevo, pero sí lo es su condición de criterio de modernidad, de una modernidad que nunca se realiza del todo.

Se entiende, entonces, que el proceso de modernización social imprima sus rasgos propios en todo aquello sobre lo que se aplica, también su transitoriedad, su capacidad de renovación. En esa medida es un dinamismo uniformador, trae consigo un aire de familia, teje una red de correlaciones, semejanzas y complementariedades sin las que el carácter total del proyecto moderno no se cumpliría. Si se me permite la apropiación del término, la modernidad es una Gesamtkunstwerk, una obra de arte total permanentemente inacabada.

Lo moderno es, pues, una perspectiva integradora de todos los fenómenos y cambios que reclaman su significado. También y de modo singular aquellos que tienen que ver con los cambios de estilo de vida y de concepto que a menudo y simplificando se entienden por estudios de género. De la importancia de estas cuestiones es buena prueba que hoy día nadie se atrevería a afirmar, como Simmel hace más de un siglo, que los contenidos de nuestra cultura poseen un carácter claramente masculino (1938, p. 12) o que la casa, el hogar, es una parte de la vida, pero la gran hazaña cultural de la mujer es haber creado esta forma universal (1938, p. 45).

He aquí la paradoja antes aludida. La desigualdad en el peso que tienen los valores masculinos y los femeninos en la cultura común choca, en primer lugar, con la ambición homogeneizadora del proyecto moderno y, en segundo, con uno de sus ideales básicos: la igualdad. Pero la cuestión no es solo si es admisible esa desigualdad, sino más bien si es posible, si todavía cabe delimitar tan claramente como hacía Simmel las aportaciones masculinas y femeninas en una sociedad realmente moderna. ¿No es lo moderno una categoría superior, capaz de redefinir la tradicional distinción 
entre lo masculino y lo femenino? ¿Es lo moderno un factor que exacerba o disuelve las diferencias? Sin duda, la historia de los últimos siglos permite responder que ambas cosas.

¿Por qué las exacerba? Tal vez porque, como decía Schiller, la cultura es voluntad de diferenciación. Para el ideal moderno de autorealización, la diferenciación es un valor ético, un signo inequívoco de libertad ejercida, cuya principal amenaza proviene de la racionalidad abstracta. En las últimas décadas se ha consolidado una cultura de las diferencias frente al denostado reduccionismo de la racionalidad moderna que habría privilegiado las identidades tanto en su aplicación teórico-científico como práctica. La carga política de esta cultura de la diferencia consiste en el rechazo de cualquier tipología o identidad que se imponga como medida y modelo, como género del que las restantes formas y tipos no serían sino concreciones imperfectas. Lo diferente no sería valorado como tal sino como negatividad respecto de lo idéntico. Ahora bien, también se sigue de esto que la diferencia entraña falta de igualdad respecto de la identidad que se erige en modelo. Por tanto, la vieja dialéctica entre racionalización (igualdad) y libertad (diferenciación) se resuelve solo si se logra pensar las diferencias sin el recurso a una identidad, esto es, si se piensa la diferencia en sí misma, y la relación de lo diferente con lo diferente (Deleuze, 1998, p. 32).

Pero, ¿es inevitablemente toda diferencia una desigualdad? Desde el punto de vista semántico, no. Hay muchas diferencias (y de distinto tipo) y también muchas formas de desigualdad. La igualdad -o la desigualdad- es una relación que se establece al menos entre dos términos y bajo una determinada razón. Lo que lleva a pensar que no todas las desigualdades son equiparables. Basta echar una ojeada alrededor para notar que unas pueden afectar a aspectos más esenciales de la persona o de la sociedad y de la justicia que otras; y también para ver cómo el contexto histórico, el paso del tiempo, pueden tanto minimizar como acrecentar la injusticia o el daño que algunas diferencias o desigualdades causan. Hay mucha desigualdad entre los tipos de desigualdades, y las diferencias no son de entrada nada sino eso, diferencias, el signo inequívoco de lo real, que diría un postheideggeriano. Como señala Ana M. González, si una diferencia -de inteligencia, fuerza, género, raza, etc.- llega a constituirse estructuralmente, no en motivo, pero sí en ocasión de una completa dominación de unos hombres sobre otros, se prescindiría de la pluralidad de contextos en que discurre la vida humana, o al menos se privilegia uno de ellos sobre los restantes de tal manera que los valores propios de ese contexto particular monopolizaran ilegítimamente los valores propios de otros contextos diferentes (González, 2009, p. 44).

La supremacía social de una diferencia -y con ella la desigualdad que introduce- sería aceptable si la actividad en cuestión está socialmente justificada por el bien común y si las restantes actividades reciben el adecuado reconocimiento social, en la medida en que también contribuyen al bien común.

¿Cómo afecta esto a la cuestión que nos ocupa? Si, como decía Tocqueville, en una sociedad fundada por el ideal de igualdad, como es la democracia moderna, la menor desigualdad se vuelve intolerable, también las derivadas de la diferencia sexual entre mujer y varón. Si la humanidad abstracta se constituye en razón o criterio de igualdad, las desigualdades resultantes de alguna forma de diferenciación son una enfermedad social cuyas causas son conocidas. Hace ya unos decenios que se procura evitar cualquier desigualdad en las formas de trato, así como en los usos lingüísticos. Igualmente, la cortesía es una virtud básica de las sociedades modernas que lleva a tratar a los otros como sujetos iguales. Según Zizek, la cortesía viene a ser la "sustancia social" de los individuos libres e independientes, pues sus reglas proporcionan el único espacio en el que la libertad puede prosperar. Como la libertad e igualdad modernas son dos figuras ideales, necesitamos de la cortesía, esto es, del fingimiento social por el que disimulamos las diferencias y desigualdades al actuar como si nos fueran impuestas desde fuera (2011, p. 27). También la cortesía, la "political correctnes" en relación a la cuestión femenina, tiene mucho de fingimiento, de hacer como si fueramos iguales, a veces hasta el extremo de convertir en una parodia la demanda de cambios en tradiciones sociales o lingüísticas.

Uno de los argumentos más usuales para solicitar o criticar la igualdad entre hombre y mujer suele ser que las diferencias son una versión adaptada de las que origina nuestra condición natural biológica. La terapia adecuada sería superar el peso de lo biológico mediante intervenciones tecno-científicas; o multiplicar las variantes sexuales de modo que sean tantas las diferencias que no permitan considerar a una como hegemónica respecto de las restantes. Pero, al determinar la diferencia como solo natural, las conductas se explican únicamente en términos de necesidad de especie. 
Esto no es suficiente. Igualmente decisivo es que la vida humana es social; esto es, como especie muestra una indeterminación originaria por lo que no se da la naturaleza humana sin más, sino siempre interpretada, esto es como cultura. Si la diferencia sexual es constitutiva del ser humano en su reciprocidad, no lo son en cambio las determinadas configuraciones de lo femenino y masculino que conocemos; en tanto que variaciones culturales pueden y deben ser aquilatadas en términos de justicia y de adecuación a un marco histórico-cultural. Por lo mismo, al ser las desigualdades fundamentalmente culturales, históricas, la terapia requerida pasa por la transformación de las estructuras sociales que las alimentan.

Al abordar estas cuestiones, Pinker recuerda la pregunta de Henry Higgins en My fair lady (1964), ¿por qué las mujeres no pueden parecerse más a los hombres? La respuesta era que estamos ante un escollo insalvable. Actualmente la pregunta se formularía de este modo: ¿no deberían las mujeres parecerse más a los hombres? Lo que sugiere que inadvertidamente tomamos el hombre todavía como punto de referencia de la mujer: nos basta con añadirle algunas características femeninas. Ahora bien, estudios científicos recientes sugieren que varón y mujer no son intercambiables:

con lo que sabemos acerca de la psicología, de la neurología y de las motivaciones económicas que subyacen a la conducta y a las elecciones de las personas (tres campos que han explotado con descubrimientos extraordinarios durante la última década), ¿es razonable esperar que las mujeres se parezcan más a los hombres? $Y$ ¿es posible que los hombres se parezcan más a las mujeres?" (Pinker, 2009, p. 17).

Para formular estas preguntas y para darles respuesta es preciso operar conceptualmente con una diferencia de significación (varón/mujer), que respeta la condición humana común, es decir, el marco lógico-conceptual de toda comparación. Cuando nos referimos a hombres y mujeres manejamos siempre abstracciones que quintaesencian la mezcla de roles, conductas, preferencias, necesidades, etc., ese entramado biológico-histórico-cultural de un ser que vive "más allá" de su condición natural. Si separamos, abstraemos para entender más y mejor, cabe preguntarse ¿es esta la diferencia inevitable? ¿no será la misma idea de humanidad una abstracción? Los estudios de neurología y psicología, como se ha indicado, insisten en la existencia de ciertos patrones ligados a la diferencia sexual. La cuestión es si esta diferenciación tiene primacía sobre las orientaciones básicas del pro- yecto moderno hasta el punto de perpetuar formas de desigualdad que impidan su realización social.

Hay quien pretende resolver la tensión entre igualdad y diferencia en relación con la mujer anulando la distinción entre lo femenino y lo masculino para equiparar la valoración de uno y otro, o, como pretenden algunas propuestas de la llamada ideología de género, para erradicar cualquier forma de dominio de lo masculino sobre lo femenino y, con ello, las desigualdades conocidas ${ }^{2}$. La respuesta podría estar en un nuevo equilibro de diferenciaciones favorecido por las expectativas comunes del proyecto moderno. En las nuevas formas de interacción y relación entre hombres y mujeres en la vida social y profesional se puede reconocer el germen de una igualdad de diversos, para la que la diferencia sexual no conlleva mayor distinción de códigos de conducta que la que se da entre personas del mismo sexo por razón de su forma de ser, profesión, etc. Pues, toda diferencia se sitúa dentro de un orden variable de diferencias, esto es, dependiente de lo que constituya el conjunto social. Sucede, entonces, que las diferencias no son vistas como negatividad, sino como simple diversidad. Igualdad y diferencia no tienen por qué ser tendencias antagónicas. Ni siquiera si la diferencia entre sexos se define por lo que cada uno afirma como relación con el otro.

Por lo demás, en las expresiones culturales que mayoritariamente han encarnado o encarnan, bien mujeres o bien hombres, descubrimos facetas de una misma realidad que se influyen mutuamente $y$ se intercambian sin que en ello tenga que verse una feminización o una masculinización ${ }^{3}$; al contrario, consolida en sus variaciones culturales e históricas una suerte de reciprocidad que constantemente ha estado presente en la sociedad humana. Uno de los registros donde más claramente se ve esta influencia o incluso trasvase de contenidos es el de las emociones. Como afirma Illouz, la mayor parte de las divisiones que organizan una sociedad se basan en culturas emocionales; es decir, la jerarquía social que sigue a la distinción de género contiene divisiones emocionales implícitas sin las que los hombres y las mujeres no reproducirían sus roles e identidades (2007, p. 17). En la medida en que los roles están cada vez menos vinculados a la condición sexuada, la adscripción de emociones típicas a unos y otras pierde relevancia y estabilidad $y$, consecuentemente, las divisiones emocionales son menos determinantes en la configuración de la identidad masculina o femenina. Y una misma emoción puede ser tan "eficaz" para interpretar una como la 
otra $^{4}$. Si la diferenciación emocional ha servido tradicionalmente para reforzar los roles y estilos femeninos y masculinos, hoy día juega un papel más relevante en las estrategias económicas, educativas o políticas.

He apuntado algunas razones que explican por qué el proyecto moderno agudiza las desigualdades, pero ¿por qué en algún sentido cabe afirmar que también las disuelve?

Si el instrumento preciso de la modernización es la racionalidad que debe regir la vida humana en todos sus niveles, de esto se sigue, entre otras cosas, la generalización de pautas de conducta y modelos de organización social, tal como viene sucediendo en las sociedades modernas. La fuerza normativa con la que se imponen ciertas conductas es reforzada por la rapidez con la que son imitadas en las grandes concentraciones de población (sean estas físicas como las grandes ciudades, sean virtuales como las redes sociales). En una sociedad expuesta a la invasión mediática, el mimetismo es máximamente eficaz desde el punto de vista de la socialización y educación cívica, y -como factor de igualación social- es, curiosamente, pacificador. Las sociedades urbanas superpobladas son el terreno abonado para la siembra de patrones de conducta, de deseos y necesidades que parecen responder a lo más propio de cada individuo, pero que se desarrollan con las mismas estrategias del mercado y el consumo, creando una especie de universalidad a partir de la suma de singulares. La previsibilidad del consumo confirma que, como señala Girard, la unanimidad es mimética (2006, p. 84).

Es notorio que el consumo y la publicidad son factores de igualación en las sociedades modernas (García, 2013; Cereda, 2013). El gran éxito del consumo reside en haberse introducido en las esferas más íntimas del individuo, vertiéndolas en un lenguaje, esto es, socializándolas: ha transformado los deseos en conductas previsibles y habituales. En la publicidad, el deseo se presenta unido a la aspiración a la vida buena, a la felicidad y autorrealización. La generalización del consumo como medio de experiencia social, la estandarización de los modelos gracias a los medios de comunicación, los avances médicos, etc., pueden ser vistos como los factores que han contribuido a agudizar la elaboración de la imagen, de la apariencia, que está presente en la vida cotidiana de todos los seres humanos. En el caso de la mujer, esta elaboración de la imagen ha estado marcada por un ideal de belleza, por encima de otros elementos configuradores de la representación cultural como la autoridad, la confianza, la simpatía, la hospitalidad... incluso por encima de la maternidad. Se habla de dictadura de la imagen, esclavitud de la imagen.
Todo esto sin duda introduce una forma de igualdad al servicio de la asimilación social que pone en peligro la identidad. El individuo singular, al no poder beneficiarse de la familia, de los orígenes o del prestigio y posición de una institución o comunidad en la que entra, debe conquistar la aprobación y reconocimiento social. Su atención está volcada hacia fuera, pendiente de las reacciones ajenas, de los signos de aprobación o reprobación. Cuanto más cambiante, más dúctil es la sociedad, más frecuente y rápidamente debe adaptar sus criterios y referencias para conservar lo ya ganado. Se puede hablar de un exceso de socialización, que lastra inevitablemente las posibilidades de individuar no solo gustos, aficiones, sino lo que es más importante, decisiones radicales sobre la propia vida, itinerarios y aprendizajes no tipificados y abiertos en lo que respecta tanto a las expectativas personales de felicidad como al triunfo social.

La modernidad y el cambio que impulsa mantienen viva la tensión entre igualdad y diferencia, pero en esta tensión no hay propiamente un espacio exclusivamente femenino ni masculino, sino que es el conjunto social, el ser humano con su diferenciación sexual el que se ve alterado, configurado por el proyecto moderno. En las páginas siguientes se destacan algunas expresiones culturales de las sociedades contemporáneas que originaria y principalmente son responsabilidad de las mujeres y, al mismo tiempo, son un angular suficientemente amplio como para ofrecer una comprensión de la entera realidad humana.

\section{CAMBIO E IDENTIDAD. LA RECONFIGURACIÓN DE LO FEMENINO Y LO MASCULINO}

Junto a la cultura de la diferencia, y como era previsible por la constante dialéctica de la modernidad, se ha insistido abundantemente en las últimas décadas en la cuestión de la identidad. Las líneas directrices de los proyectos de investigación subvencionados por entidades públicas tienen entre sus temas prioritarios el de la identidad. Todo ello sugiere que esta no es solo una problemática de interés transversal, sino una dimensión de la autocomprensión humana que, por causas que ahora no toca analizar, es exigida para el pleno desarrollo tanto de la existencia individual como de las sociedades modernas.

Si como veíamos al comienzo, la modernidad está semánticamente unida a la idea de cambio, lo mismo acontece con la moderna existencia humana. Pese a la confianza del romanticismo en la capacidad de cada hombre para llevar a cabo su vida como un proyecto único, la subjetividad humana revela una for- 
ma de fragilidad hasta hace un par de siglos apenas advertida: la identidad y con ella la identidad femenina y masculina. Sin duda, podemos afirmar que se ha producido una reconfiguración de lo femenino y lo masculino que, entre otras cosas, hace evidente la dependencia cultural de los antiguos arquetipos. Para recordar las variaciones históricas y culturales de las modalidades de feminidad y masculinidad basta con acercarse a un museo de arte, a la historia de la literatura, a las tradiciones de trato social o la más reciente historia del cine. Unas suceden a otras como consecuencia de distintos cambios.

Sin embargo, sostengo que la modernidad social no trae sin más variaciones en los modos de vivir la condición de mujer y varón tal como se ha dado siempre a lo largo de la historia, sino que da lugar a una reconfiguración de la identidad masculina y la femenina. El término "reconfiguración" connota el significado de cambio, modificación, y al mismo tiempo el de reinicio, un empezar de nuevo. ¿En razón de qué se puede hablar de un "empezar de nuevo", de reiniciar las formas de identificar y diferenciar lo masculino y lo femenino? Únicamente si esa reconfiguración no es el resultado de un simple proceso de adaptación social, ni la huella del impacto del cambio cultural en las relaciones humanas, sino que es exigida por la propia condición humana; si es el resultado de una transformación operada desde dentro en las mujeres y hombres de las últimas décadas, y en la que ellos han tenido que ser -no les ha quedado otra opción- los agentes principales.

Aun a riesgo de simplificar, sostengo que las modalidades en las que se ha expresado la identidad de la mujer moderna tienen en su raíz el mismo factor dominante de las identidades modernas masculinas: la aspiración a la realización individual y la consecuente exigencia de libre disposición de la propia existencia. Este factor es común a mujeres y hombres; por ello, a lo largo de este último siglo, la imitación de estilos y lenguajes entre unos y otras ha sido constante y recíproca. Podría decirse que se han mirado menos entre sí y, en cambio, han atendido a un modelo de humanidad en la que primen libertad, autonomía, racionalidad (esto es, en cierto modo un modelo de humanidad asexuada). Las sociedades ultramodernas activan algo así como una coerción a la libertad, en expresión de Bauman. Sin distinción de sexo, todos se ven urgidos a elegir y decidir como si esto garantizara alguna forma de felicidad, más aún, como si fuera el requisito para ella (2002, p. 64). Se trata de elegir entre estilos y modelos diversos que conviven en la indistinción valo- rativa y provisionalidad extrema. Una vez que el ritmo de los cambios sociales se ha acelerado, coincido con Burggraf en que el verdadero problema de nuestro tiempo no consiste "en la búsqueda de la emancipación, sino en la de la identidad" (1999, p. 49).

Precisamente por esto en nuestro tiempo, como en ningún otro momento de la historia, se ha vivenciado con los rasgos de una crisis personal la búsqueda de la identidad, que requiere de la adopción de códigos y pautas diferenciadas sexualmente. $Y$ con ello no me estoy refiriendo estrictamente a la cuestión de la homo o heterosexualidad, sino a un fenómeno más amplio que afecta a todo individuo nacido tras la segunda mitad del siglo XX en países de cultura occidental. Sucede que las conductas diferenciadas sexualmente, que en otras épocas eran suficientes para orientarse en la vida privada y pública, resultan insuficientes en el nuevo contexto de las ciudades modernas, donde el trabajo y la formación rigen las relaciones sociales y la familia tiene como principal responsabilidad el desarrollo correcto del yo, de su vida emocional y sentimental.

Desde la perspectiva que representa Simmel -y todavía en la época que él analiza-, la expresión "vida emocional y sentimental" parece aludir casi únicamente a una dimensión existencial de la población femenina y, en todo caso, al periodo de adolescencia y primera juventud de los varones. En la actualidad se habla sin restricciones de ningún tipo de una cultura emocional que afectaría a todas las esferas de la vida social, económica, política, etc. (Mestrovic, 1997). El protagonismo de las emociones en la vida social permite afirmar que estamos ante un cambio de régimen emocional en las sociedades tardomodernas (González, 2013, p. 10). Interesa destacar que no estamos propiamente ante una feminización de la sociedad, es decir, ante una forma de epidemia por contagio de una parte al todo social. Se trata de un fenómeno que involucra por igual a hombres y mujeres, porque no nace ni se alimenta de la diferencia sexual, sino que responde a una etapa madura de la entera transformación de lo público y lo privado que ambiciona el proyecto moderno.

La valoración positiva de emociones y sentimientos, el reconocimiento de su aporte cognitivo (Nussbaum, 2008 , p. 21) explican que paulatinamente haya perdido peso social la comprensión racional de lo justo o conveniente en general: las emociones son a su manera un juicio. Mientras que la idea de igualdad y racionalidad social preside el imaginario que sustenta nuestro sistema y cultura políticos, y sobrevive prin- 
cipalmente en los movimientos reivindicativos de derechos, la cultura popular (la cultura artística) invita a códigos privados, a criterios individuales, a crear tendencias (Flamarique, 2012). La protección y el cultivo de la vida íntima, de la vida para sí, constituye la tarea fundamental si se quiere alcanzar el equilibrio y madurez, y se recomienda como parte del aprendizaje de la vida. Este repliegue en la esfera privada no es ajeno a la imperiosa necesidad de forjar la propia identidad desde la complejidad (y provisionalidad) de las orientaciones que ofrece la esfera social y la profesional. Como afirma Lipovetsky, con el repliegue hacia la esfera privada se ha producido el fin del homo politicus y el advenimiento del homo psicologicus que solo cree en su bienestar (1983, p. 130).

¿Cómo se reconocen estos cambios en la "cultura femenina"? Las primeras manifestaciones de ese giro emocional a la esfera del yo por encima del grupo o la clase social se localizan en el desajuste en la percepción y valoración de las mujeres occidentales sobre su vida doméstica como amas de casa, esposas y madres que se detecta a partir de los años 50 especialmente en los países desarrollados. Este desajuste se articula en un discurso que encuentra una rápida acogida en las nuevas generaciones. El cine o la literatura dan buena muestra de ello ${ }^{5}$; pero más significativo es que, ante ese sentimiento de insatisfacción radical, de frustración en mujeres que disponen de adelantos técnicos como en ninguna otra época, en un momento de mayor disponibilidad de electrodomésticos, y menor carga familiar, proliferen los libros de autoayuda y consejos sentimentales (Hochschild, 2008).

Cabe preguntarse ¿cuál es el origen cultural de ese descontento? Una respuesta simple -pero no por ello falsa- sería la misma modernización que ha transformado el imaginario social e individual, y al mismo tiempo está diluyendo la frontera de lo público y lo privado. ¿Cómo establece la cultura, mediante qué reglamentación de sentimientos, lo que deberíamos sentir o no, lo que creemos sentir? En buena medida a través de las tipologías de lo masculino y lo femenino y las divisiones emocionales a las que me he referido antes. Una de las tipologías que se quiebra en la segunda mitad del siglo XX es la que responde a "la mística de la feminidad" según una expresión de Betty Friedan (1963): lo femenino sería la esencia de las mujeres Ilamadas a la maternidad y a dedicarse a las tareas correspondientes. Si las mujeres que viven más de acuerdo con ese ideal de feminidad son las menos satisfechas, es porque la aspiración a la autonomía e igualdad se ha introducido poco a poco en el lenguaje y los modos expresivos con los que las mujeres proyectan su existencia. El desarrollo de una vida profesional acorde con la formación recibida sustituye en el abanico de sus expectativas al deseo de formar y cuidar de una familia. Los estilos de vida desde los años 60 y 70 del pasado siglo vinculan libertad con desinhibición: los anuncios de moda o los personajes de éxito en el cine proponen mujeres y hombres activos, que no se sienten constreñidos por convenciones ni formas de trato heredadas de la generación anterior. La falta de modelos y referentes claros, las tensiones que en cualquier caso produce la vida moderna -tanto en la esfera laboral como familiar- están detrás del difícil camino de las mujeres hacia su plena instalación social.

Las mujeres habrían sido pioneras en la incorporación de lo que Illouz llama el "estilo terapéutico emocional" a su ámbito más personal. Este estilo terapéutico consiste en el desarrollo de técnicas específicas (lingüísticas y científicas) para comprender y manejar las emociones, principalmente en las relaciones humanas (2007, pp. 22-23). Los libros de autoayuda quieren dirigir el enfoque femenino de la vida íntima. En la actualidad hay un mayor desconcierto ante los problemas emocionales por la pérdida de peso relativo de familiares, sacerdotes, etc. "Ese lugar lo ocupan los libros de autoayuda: son asesores de inversión emocional" (Hochschild, 2008, p. 27) que aconsejan cada vez más un enfriamiento: al reafirmar el ideal de la igualdad socavan otro, el del compromiso. Lo paradójico es que la terapia no trata de eliminar el problema, las emociones, sino de transformarlas mediante una racionalización de la vida emocional.

En este terreno las mujeres han jugado con ventaja. Los códigos tradicionales de la forja de la identidad femenina han potenciado el lenguaje emocional. Avanzado ya el siglo XXI no cabe duda de que esas mismas tensiones, la volatilidad de los estilos de vida y el cambio de régimen emocional afectan con igual intensidad a los hombres.

El repliegue al mundo interior, la preocupación por la gestión de la vida personal y profesional se dan tanto en los hombres como en las mujeres. Están detrás de ese fenómeno de nuestro tiempo que Hochschild ha denominado la "mercantilización de la vida íntima", que puede resumirse en la generalización de dos modelos de "inversión en emociones": invertir en el capital doméstico o invertir en el yo como una empresa individual (2008, p. 39). Aunque su objeto principal de análisis son las mujeres, las dinámicas que describe se advierten con pocas diferencias en 
el mundo masculino. Tanto la mujer como el hombre del siglo XXI aplican a su apetito, a su cuerpo, a su amor una disciplina ascética, ejercen una forma de autoexplotación. El sujeto como empresario de sí mismo no es capaz de establecer relaciones con los otros que estén libres de una finalidad (Han, 2014, p. 13). Se impone la aspiración a un yo-autosuficiente que desea un tu-autosuficiente.

Hochschild identifica las condiciones que favorecen el espíritu mercantil de la vida íntima: el debilitamiento de la familia, la decadencia de la iglesia, la pérdida del localismo comunitario. "Contra este telón de fondo se instala una cultura mercantil que toma silenciosamente del feminismo la ideología que ha abierto el camino para que las mujeres ingresen en la vida pública" (Hochschild, 2008, p. 41). Todo esto habría llevado a una instrumentalización del amor, a la continua evaluación del capital psicológico y a la inversión en uno mismo. Por lo que las relaciones hombre-mujer se miden con cautela, con precaución. En sentido parecido, Han habla de "poder inteligente" que apuesta por la organización y optimización del propio yo, realizadas de forma voluntaria y con la intención de agradar y generar dependencias (Han, 2014, p. 30).

Desde la cuestión que enmarca este apartado, la configuración de lo femenino y lo masculino en una sociedad sometida a cambios orientados por el espíritu de la modernidad, habría que decir con Hochschild que las mujeres han asimilado las reglas masculinas del amor, como ser más "fríos", posponer el enamoramiento, dejar que el amor desempeñe un papel menos central, manejar las emociones para postergarlas. La cultura femenina se ha acercado con más rapidez a la masculina de lo que esta ha aprendido de los códigos femeninos. "En lugar de humanizar a los hombres, capitalizamos a las mujeres. Si el concepto de revolución estancada nos lleva a preguntarnos cómo ha de alcanzarse la igualdad, el concepto de espíritu mercantil de la vida íntima plantea otra pregunta: ¿iguales en qué términos?" (Hochschild, 2008, p. 45). La respuesta obvia sería que en lo que respecta al proyecto vital, a la autorrealización, la balanza se inclina por la prevalencia de modelos masculinos. Algunas profesiones no solo han sido casi exclusivamente masculinas, sino que exigen mayores dosis de ambición y competitividad para un desarrollo exitoso, que las consideradas tradicionalmente propias de las mujeres. Para mantenerse en las primeras es preciso adoptar los códigos masculinos que regulan las relaciones profesionales y sus valoraciones implícitas. En el mundo laboral los códigos de género pueden apa- recer como un escollo que deber ser vencido. Todavía en el siglo XXI las mujeres oscilan muchas veces entre el código aprendido en el ámbito familiar, en el que está diferenciada la autoridad masculina y la entrega femenina, y el código que responde al presupuesto de la igualdad, y quita peso a las diferencias entre hombres y mujeres (Hochschild, 2008, p. 75). Pero, en la medida en que este código toma sus elementos y reglas de la mayor experiencia y práctica masculina, supone una pérdida, una forma de negación que explica la mayor fragilidad de las mujeres frente a las tensiones entre la vida profesional y la personal.

No obstante, la existencia moderna se desenvuelve en un entramado social que acoge tanto el desarrollo afectivo, los sueños y proyectos personales como la vida familiar y profesional. Las nuevas relaciones familiares, sociales, y laborales han favorecido experiencias y aprendizajes sobre el arte de vivir como varón o mujer que en absoluto son negativos. Cabe preguntarse todavía ¿qué hemos aprendido e imitado con éxito los hombres de las mujeres y viceversa en la convivencia familiar y profesional?

\section{LOS ESCENARIOS COMPARTIDOS DE LA FAMILIA Y EL TRABAJO}

La incorporación de la mujer al mercado laboral, su creciente profesionalización y la inserción del trabajo en el horizonte vital de las mujeres, con expectativas, exigencias y ritmos semejantes a los de los varones, constituye una auténtica revolución social que ha modificado tanto los parámetros y procedimientos de la esfera pública y económica como los de la esfera privada, familiar y personal. Aquí solo quiero fijar la atención en algunos aspectos donde esa revolución deja una huella clara de las transformaciones operadas. Entre otras, el espacio físico: actualmente la mujer pasa la mayor parte de su tiempo fuera del hogar, en ese espacio antiguamente considerado propio de la vida pública, esto es, masculina. Si con la revolución industrial se inicia esa separación entre la casa y el lugar de trabajo, que afectaba casi exclusivamente a los varones (Sennet, 2000, p. 33); ahora, esta separación caracteriza también el día a día de las mujeres. Pero esto no solo no ha disminuido la importancia del "dentro", de la casa, en la existencia moderna, sino que también el espacio de la vida familiar se ha estructurado de acuerdo a las ausencias y nuevos modos de presencia de sus ocupantes.

La salida del ámbito doméstico es vista por algunos como una pérdida para el todo social y no solo para la mujer. Según Simmel, la feminidad solo se preserva en 
el ámbito doméstico. Y, por eso, la mujer está siempre consigo misma en su casa, mientras que el varón busca su casa siempre fuera de sí mismo (Simmel, 1938, p. 93). Algo cercano sostiene la pensadora feminista Luce Irigaray cuando afirma que con la incorporación de la mujer al mundo laboral masculino se ha dado una pérdida de la identidad femenina (Irigaray, 1990, p. 343). Hochschild, en cambio, sostiene que la incorporación de la mujer al trabajo asalariado explica que valores tradicionalmente considerados femeninos tengan espacio en el ámbito laboral (habla de una feminización de la fuerza de trabajo) y que las mujeres hayan interiorizado valores tradicionalmente considerados como masculinos, propios del trabajo (2008, p. 274). Sin duda estamos ante un intercambio de doble dirección de bienes y valores entre la esfera privada, el hogar y el trabajo que repercute lógicamente en la autocomprensión de las mujeres, pero simultáneamente en la de los varones y en el conjunto social. Pues modifican patrones de conducta, modos institucionalizados de relación social y económica que afectan a todos, en todas las etapas de la vida humana.

Para la mayoría de nuestros contemporáneos, la esfera privada, concretamente el hogar, representa cada vez más el espacio para el libre desarrollo personal frente a las exigencias de la vida profesional. El hogar, la casa como refugio, iguala las aspiraciones y posibilidades de dedicación de varones y mujeres que pasan buena parte de su tiempo fuera. Es también una fuente de tensiones que generalmente pesa más sobre las mujeres que sobre los varones. Compartir la aspiración profesional favorece otras formas de relación y dependencia de hombres y mujeres que ya no miran al sostenimiento de la familia, sino a la aspiración de felicidad personal; por lo que se hace imprescindible un nuevo equilibrio de igualdad y diferencia entre los miembros de una familia. Los pasos en esa dirección son muy interesantes. En los últimos decenios se ha llamado la atención sobre una de las dimensiones tradicionalmente en manos de la familia que el nuevo estilo de vida pone en peligro: el cuidado y atención de sus miembros más débiles por edad, enfermedad, etc. Basta observar cómo hombres y mujeres se comportan en sus relaciones familiares para darse cuenta de los cambios notables en las conductas distribuidas entre unos y otros. Por ejemplo, ellos se han apropiado de tareas y conductas antes solo femeninas (en el cuidado de los niños, la supervisión de animales domésticos, la compra del supermercado, la decoración, consejos de estilismo, etc.). Ellas tienen una mayor presencia y credibilidad en las cuestiones más "técnicas" que afectan al desarrollo personal de los hijos o a la vida doméstica. Estudios recientes, de los que se tienen datos cuantitativos, muestran que las horas efectivas de dedicación a los hijos por parte de los padres (hombres y mujeres), su implicación en el día a día, ha crecido de modo considerable en los últimos dos decenios. También ha aumentado el nivel de preocupación y sentido de responsabilidad sin que haya una causa externa identificable. Este crecimiento -sin desmerecer otros factores de tipo cultural, estructural y económico- apunta más bien a la consolidación de un nuevo concepto de paternidad y maternidad (García-Manglano, Nollenberger y Sevilla-Sanz, 2015).

Con todo, es indudable que la escasez de tiempo para la casa, para la vida familiar, está detrás del auge y crecimiento del mercado de servicios "familiares" de toda índole con el que se quiere suplir la falta de tiempo y de atención de los padres a los hijos. También este aspecto ha sido estudiado brillantemente por Hochschild (a quien sigo en sus líneas principales). Si la incorporación de la mujer al mundo laboral ha dejado vacía la casa, su ausencia ha contribuido a que la familia se convierta en un ideal, un símbolo potente de cualidades apreciadas, tales como la empatía, el reconocimiento y el amor: cualidades que son la quintaesencia de lo personal y que el mercado de servicios debe imitar (2008, p. 51). Por lo mismo en esa oferta de servicios no se hacen la competencia empresas semejantes, sino que estas compiten con la familia y, en particular, con el rol de esposa-madre supliendo sus funciones de modo creciente. La dinámica de crecimiento de este tipos de servicios es sencilla: a medida que la familia se minimiza y es incapaz de prestar la atención que se le demanda, se recurre al mercado para conseguir lo que necesita y de este modo se minimiza todavía más la función social de la familia.

La simbolización hiperbólica de la madre es en parte una respuesta a la desestabilización del basamento cultural y también económico sobre el que se asienta la familia (...) Cuanto más se endurece el mundo exterior, más anhelamos que el hogar se convierta en un refugio. El símbolo de la madre es eficaz (Hochschild, 2008, p. 63).

\section{¿Estamos ante una nueva paradoja?}

Los llamados "valores familiares" cotizan al alza, pero la estructura familiar en la que han florecido es minoritaria hoy día o está en fase de transformación: así que no sabemos quiénes deben ser sus principales agentes. Todavía hasta la década de los sesenta (para ello basta ver el cine, la publicidad, la televisión) eran tarea de mujeres. En la actualidad-separados estos 
valores de la maternidad- deben ser asumidos por cualquiera o por todos los miembros de una familia. Ejemplos notables los tenemos en las calles de cualquier ciudad, en la literatura, en el cine. Es interesante observar cómo esto ha permitido ensayar otros modos de establecer las relaciones afectivas, de asumir el cuidado y la atención a la familia, las prácticas de ocio compartidos por igual por varones y mujeres. También que entre las nuevas generaciones la familia sea la institución que más se aprecia. Si alguien ha pensado que las empresas de servicios familiares iban a suplantar la familia, y reducir sus tareas casi a cero, no parece que esa tendencia se consume.

Quiero detenerme en otro signo del cambio social, que a priori parece más propio de la cultura femenina que entró en crisis, pero que afecta por igual a toda la sociedad. Como hemos visto, el eje familia-trabajo une y separa las dos dimensiones que han pasado a capitalizar la vida moderna y que afectan íntimamente a mujeres y hombres sin exclusión. La ambición profesional como parte esencial del desarrollo de la persona, la dedicación al trabajo, la supeditación de proyectos familiares o sentimentales al ritmo y planificación laboral, la expectativa de reconocimiento a través de la profesión y, consiguientemente, la mayor estima de la valoración profesional sobre el aprecio del círculo familiar, todos ellos son rasgos que definen por igual a hombres y mujeres de nuestro tiempo. En esa misma medida el modo como se defina el eje familia-trabajo es responsable principal de la identidad personal.

En las últimas décadas, se ha analizado al detalle lo que se llama cultura empresarial: esto es, el tipo de vida, relaciones, códigos y valores que caracterizan a cada empresa y le confieren una determinada personalidad, sobre todo para sus empleados. Llama la atención que se ha asumido como algo normalizado el contagio de los valores familiares al mundo laboral. Como explica Hochschild, "la empresa tomó prestados elementos culturales de la familia y de la comunidad". Muchas empresas reclaman una dedicación plena de tiempo y capacidades fomentando su desarrollo; además, esperan y exigen un alto grado de compromiso por parte del trabajador, haciéndole responsable del buen ambiente dentro de la empresa y del logro de los objetivos comunes. El giro empresarial es algo sin vuelta atrás. Se tiene en alta estima la cooperación entre los trabajadores, el trato amistoso para el trabajo en equipo, el bienestar de los empleados y de los clientes. Al ofrecer cada vez más servicios internos/ privados a sus empleados, su cultura de trabajo es "maternal" (Hochschild, 1997, pp. 19-20).
Ahora bien, esta tendencia en la cultura de empresa que incorpora ciertos valores familiares - como la amistad o el desarrollo personal - alarga la jornada de trabajo: deja, por tanto, cada vez menos tiempo para el cuidado de familia y hogar, en general. En consecuencia, el trabajo profesional es la fuente primordial de reconocimiento y satisfacción personal como ya no lo es la vida familiar, ni siquiera para las mujeres; allí, en el hogar, esperan tareas y cargas debidas, para las que apenas se tienen fuerzas o tiempo. Si el trabajo ofrece posibilidades inagotables de crecimiento, la familia/hogar impone obligaciones (Hochschild, 1997). He planteado de modo algo dramático la resolución de la doble orientación de la vida moderna hacia la profesión y la esfera íntima-personal para subrayar que el desequilibrio gravita sobre la familia, el hogar; es decir, sobre el espacio físico y mental ocupado por las mujeres hasta hace un siglo. Antes he mencionado la ausencia de la mujer y el crecimiento de las empresas de servicios, por un lado, y la mayor implicación de los varones en las tareas de cuidado y atención en el ámbito familiar, por otro. Esas realidades conviven con esta otra: hombres y mujeres buscan reconocimiento en el trabajo y muchas veces ven las tareas de atención familiar y domésticas como algo pesado y sin beneficio personal. Con palabras de Hochschild, "en el trabajo encontramos una familia y vemos la familia como trabajo" (2008, p. 280).

Si los dos pilares de la concepción moderna del hombre son la libertad y la autonomía que cristalizan vitalmente en la orientación hacia un proyecto de vida personal, se entiende que para los hombres y mujeres de nuestro tiempo sea cada vez más difícil conjugar el "nosotros". Norbert Elias ha llamado la atención sobre el cambio experimentado en la Europa moderna:

antes el equilibrio entre la identidad del nosotros y la identidad del yo se inclinaba más hacia la primera. A partir del Renacimiento, el equilibrio empezó a inclinarse cada vez más hacia la identidad del yo (Elias, 1990, p. 226).

El lugar destacado donde se advierte este desequilibro es la familia, pues tiene un papel central tanto respecto a la identidad del nosotros como a la del yo. Todo esto coincide con la transformación de la familia en los entornos urbanos en nuclear, limitada a padres e hijos, como una comunidad definida por los lazos afectivos entre sus miembros. En efecto, perdida la función social de situar a sus miembros de manera objetiva en el orden social que demarca el "nosotros", la familia constituye el escenario simbólico que expresa de forma extraordinaria la propia individualidad, ofrece los primeros modelos para desarrollar el yo (Illouz, 2007, p. 25). 


\section{ARQUITECTURA SENTIMENTAL: HOMBRES Y MUJERES, LO COMÚN Y LO DIFERENTE}

En este último apartado quiero tocar un aspecto característico de la formación de la identidad, el imaginario afectivo-sentimental, que con frecuencia se considera lo paradigmático de la condición femenina. Como trataré de mostrar, si alguna vez lo fue, ahora ha dejado de ser un cuestión menor y particular de la identidad de las mujeres, y opera también como medida del desarrollo identitario de los varones.

Si los cambios en los modos de establecer las relaciones sociales son otro de los rendimientos del proceso de modernización que han sufrido las sociedades occidentales en los últimos dos siglos, especialmente significativos son los cambios en las relaciones sentimentales. Además de factores propiamente sociológicos, ligados a los estilos de vida urbanos, a la mayor movilidad (geográfica y social) y a la variedad de procedencias y culturas de los habitantes de las ciudades, la concepción del ser humano como una individualidad libre es lo que está detrás de la demanda y consumo de literatura romántica que favorece el rápido desarrollo de un público de lectoras. En este tipo de novelas, las mujeres veían reflejadas y formuladas sus propias necesidades afectivas. Aprender a amar y a entender el amor a través de la ficción novelesca, por ejemplo, es la llave que da paso a la interiorización del sentimiento: la lectura es una actividad que cuando se realiza a solas, favorece una forma de meditación, de interiorización que actúa condicionando por completo la educación sentimental. Un ejemplo clásico en esta dirección lo ofrece la novela de Flaubert, Madame Bovary. La situación y los personajes reflejan los cambios iniciados unas décadas antes, que constituyen el germen de lo que se suele llamar educación sentimental.

He mencionado en el apartado anterior algunos fenómenos que enlazan directamente con este tema: el cambio de régimen emocional, la valoración al alza de las emociones en las sociedades contemporáneas y la centralidad de los lazos afectivos en la familia y, por tanto, en el matrimonio. Esto último venía ya gestándose desde comienzos del siglo XIX, pero es en el $X X$ cuando el amor se convierte en el único significado legitimador del matrimonio. Pese a que la visión romántica del amor ha sufrido cambios en estos dos siglos, no ha disminuido su predominio tanto en la literatura como en la cultura popular. La imitación de las idealizaciones de la vida sentimental que presenta la cultura popular forma parte del aprendizaje e iniciación en la vida adulta. Aunque algunos elementos y rituales son comunes, se dan ciertas variantes en el universo masculino y en el femenino. El sentimiento ideal, es decir, elaborado y ritualizado, condiciona lo que se quiere sentir, y cómo se debe expresar, si bien muchas veces la experiencia real lo desmienta.

Es obvio que estos cambios han tenido un impacto mayor en las mujeres, al menos hasta hace poco. Basta considerar los primeros indicios de esta revolución y sus efectos en novelas de finales del siglo XVIII (como Lucinde, de Friedrich). La independencia y libertad del corazón que reclaman las mujeres para elegir marido son vistas como una grave amenaza al orden social establecido. Desde la altura del siglo XXI se puede decir que este protagonismo de las mujeres en la vida sentimental fue el primer paso hacia una presencia social similar a la de los varones. La nueva arquitectura sentimental, como no podía ser de otro modo, introdujo cambios en los modos de trato y de cortejo, así como en las expectativas y concepto del amor por parte de los hombres. A primera vista se podría decir que el nuevo código sentimental femenino se impuso socialmente, de modo que "socialmente" los varones no tenían otra opción que jugar de acuerdo a sus reglas. La cuestión tiene más calado pero no es este el punto en el que me quiero fijar, sino en los códigos actuales.

¿Dónde estamos hoy? La potente fascinación que ejerce la experiencia romántica sobre hombres y mujeres responde a que, como señala Illouz en su libro (tan acertadamente) titulado ¿Por qué duele el amor?, los motivos que hacen del amor un elemento central de la identidad y felicidad son casi los mismos que lo determinan como un ámbito especialmente difícil de la experiencia: se trata de los modos institucionalizados del yo y la identidad moderna (2012, p. 15). Los fracasos sentimentales afectan, por tanto, al núcleo íntimo de la persona; ante ellos, nuestros contemporáneos ponen en marcha todos los recursos disponibles: terapéuticos, estratégicos, educativos, comerciales: es decir, las distintas formas de racionalidad que impregnan la vida moderna en todas sus dimensiones.

Libertad y autonomía, las dos marcas del ADN moderno, están detrás del imaginario sentimental que, en lo esencial, no es ni femenino ni masculino ${ }^{6}$. Con todo, aunque el amor sea en primera instancia un asunto íntimo, hombres y mujeres identifican los elementos con los que diseñar las relaciones amorosas en los modos institucionalizados. Siempre ha sido así, se me puede objetar, pues la práctica del romance y del matrimonio se encuentra configurada por la sociedad y la cultura. No obstante, hay algo "significativamente moderno" 
en las prácticas actuales. En páginas anteriores me he referido al modo como el mercado y el consumo ha penetrado e informado las dinámicas del deseo y las emociones. No podía ser menos respecto al amor y las expectativas de plenitud que le acompañan. Por eso, algunos autores han llegado a afirmar que el amor es un fenómeno capitalista, una inversión emocional orientada al beneficio (Precht, 2012); o, como dice uno de los personajes de la ficción televisiva, ha sido inventado por las agencias de publicidad (Mad Men). En lo que estas posturas coinciden es en señalar el carácter de representación del amor romántico; carácter que se ha visto reforzado por la recreación de ese ideal (o ideales) en la cultura popular, esto es, en la literatura, la música, el cine, la televisión y no en menor medida en la "prensa del corazón". Las representaciones ofrecen la imagen del amor: por un lado, el amor inquebrantable y, por otro, el amor como utopía de expresión y libertad, como aventura. En otro de sus libros E. Illouz ha tratado desde la perspectiva sociológica los modos en que la sociedad del capitalismo avanzado vincula el desarrollo del romance a determinadas prácticas de consumo. Lo interesante es ver cómo esas idealizaciones románticas que están vigentes en el imaginario social desde el siglo XVIII claramente, han sido ordenadas por el exitoso encuentro entre las ilusiones románticas y el mercado, de modo que se ha consumado una cierta igualdad en la dependencia que hombres y mujeres tienen de los códigos y estrategias amorosas (Illouz, 2009, p. 50).

Las narrativas televisivas y cinematográficas, que reflejan la vida y, al mismo tiempo la configuran, proporcionan inagotable material de consumo de tipologías sentimentales: las que responden a la sensibilidad romántica -se vive el amor como "revelación" y se pasa la vida en espera de un gran relato de amor eterno; las que expresan la forma de vivir el amor como aventura, con una fuerte carga emocional y de riesgo. Recientemente ha emergido la tipología del single: un individuo, hombre o mujer, que ya ha renunciado al amor pleno, y no busca su continuación vital. Es el tipo que habita ahora las grandes ciudades.

En este fenómeno se pone de manifiesto una suerte de devotio posmoderna o, dicho de otro modo, el recogimiento fervoroso del individuo sobre sí mismo. (...) Pienso sobre todo en todos aquellos que conducen su vida en solitario como una filosofía, y que son algo así como monjes incrédulos, monjes de la falta de fe en relaciones sociales. No hay más que un axioma en la práctica: los placeres del instante son, efectivamente, placeres del instante" (Sloterdijk, 2003, pp. 46-47).

La paradoja está servida. La modernidad, que alimentó el sueño de una felicidad y bienestar universales, es también responsable de la tensión que surge de las dos exigencias mencionadas ${ }^{7}$ : por un lado, la que vincula amor logrado e identidad personal (lo que hace enormemente frágil el equilibro emocional tanto de hombres como de mujeres); y, por otro, la que establece distancia y cálculo, precisamente porque es la felicidad de uno lo que está en juego. En lo que respecta a las estrategias, a la racionalización de los sentimientos en orden a la prosecución de fines, no coinciden plenamente las lógicas que siguen hombres y mujeres.

A lo largo de estas páginas me he fijado en algunos cambios de los modos de ser y de relacionarse individual y socialmente de las mujeres que por su carácter "moderno" alcanzan a toda la condición humana y permiten comprender mejor los estilos de vida actuales.

\section{NOTAS}

1. "El hecho de ser mujer es más esencial que para el hombre el hecho de ser hombre (...) para la mujer la sexualidad consiste en ser" (Simmel, 1938, p. 96).

2. “En cualquier caso, el punto teórico más frágil de los discursos de género estriba en un escaso refinamiento conceptual, que lleva a considerar la dominación como algo inevitablemente derivado de la diferencia, para concluir a continuación que la anulación de la diferencia es el único camino para superar la dominación. Esta hipótesis es radicalmente problemática por utópica, pues olvida que la diferencia -no solo la diferencia de género sino cualquier diferenciaacompaña necesariamente el despliegue de la vida social, de forma que el intento de suprimir una diferencia significa únicamente introducir otra". (González, 2009, p. 43).
3. En su libro Un hombre enamorado, el escritor noruego K. O. Knausgard hace unas observaciones interesantes al respecto.

4. En un estudio recientemente publicado, La distancia entre Marte y Venus, psicólogos italianos y británicos han aplicado una escala de 15 rasgos de personalidad a una encuesta mucho más general realizada a 10.200 estadounidenses, la mayoría de raza 


\section{NOTAS}

blanca y con un nivel de estudios superior a la media en su país. Los datos obtenidos indican que, de media, las mujeres son más sensibles que los hombres y también son más cordiales y más aprensivas o ansiosas. Por el contrario, los hombres puntúan más en rasgos como la estabilidad emocional, la dominancia, la atención a las normas y la vigilancia. Sin dar estos datos por definitivos consideran que estas diferencias son significativas. (Cf. "La sensibilidad es lo que más diferencia a hombres y mujeres", www. elpais.10.enero.2012).

\section{BIBLIOGRAFÍA}

Bauman, Z. (2002). La ambivalencia de la modernidad y otras conversaciones. Barcelona: Paidós.

Beriain, J. (1989). El ser oculto de la cultura femenina en la obra de Georg Simmel. REIS - Revista Española de Investigaciones Sociológicas, 89, pp. 141-180.

Burgraff, J. (1999). Mujer y hombre frente a los nuevos desafíos de la vida en común. Pamplona: Eunsa.

Cereda, A. (2013). El consumidor de publicidad. En: Flamarique, L. y D'OliveiraMartins, M. (eds.) Emociones y estilos de vida. Radiografía de nuestro tiempo. Madrid: Biblioteca Nueva, pp. $197-$ 210.

Deleuze, G. (1998). Diferencia y repetición. Madrid: Jucar.

Elias, N. (1990). Cambios en el equilibrio entre el yo y el nosotros. En: Elias, N. La sociedad de los individuos. Barcelona: Península.

Flamarique, L. (2012). From the Psychologization of Experience to the Priority of Emotions in Social Life. En: González, A. M. (ed.). The Emotions and Cultural Analysis, London: Ashgate, pp. 51-67.

Flamarique, L. (2015). A Revolution in Urban Lifestyle: Mad Men's Narrative Revisited as a Social Lab. En: García, A. N. (ed.). Emotions in Contemporary TV Series. London: Palgrave, pp. 152-170.

García, A. N. (2013). La relación de mercado y las emociones en el consumo. En: Flamarique, L. y D’Oliveira-Martins, M. (eds.) Emociones y estilos de vida. Radiografía de nuestro tiempo. Madrid: Biblioteca Nueva, pp. 29-53.
5. Un excelente relato sobre este malestar y los cambios sociales anejos lo ofrece la serie de televisión Mad Men (Flamarique, 2015).

6. Sobre las diferencias en el modo de "sufrir" por amor de los hombres y mujeres de nuestro tiempo, cfr. el ensayo de E. Illouz (2012).

7. Una peculiar combinación de ambas exigencias se advierte en la descripción que hace Sloterdijk del single por excelencia: "La vida trabaja sobre nosotros como un cerrajero forjando una llave extremadamente complica-

García-Manglano, J., Nollemberger, N. y SeviIla-Sanz, A. (2015). Gender, Time-Use and Fertility Recovery in Industrialized Countries. En Wright, J. D. (ed.). International Encyclopedia of the Social \& Behavioral Sciences (Second Edition), pp. 775-780.

Girard, R. (2006). Los orígenes de la cultura. Madrid: Trotta.

González, A. M. (2009). Género sin ideología. Nueva Revista, 124, pp. 42-52.

González, A. M. (2013). Introducción: emociones y análisis social. Flamarique, L. y D'Oliveira-Martins, M. (eds.) Emociones y estilos de vida. Radiografía de nuestro tiempo. Madrid: Biblioteca Nueva, pp. 9-24.

Habermas, J. (1988). Modernidad versus postmodernidad. En: Picó, J. (comp.) Modernidad y postmodernidad. Madrid: Alianza, pp. 87-102.

Han, B.-C. (2014). Psicopolítica. Neoliberalismo y nuevas técnicas de poder. Barcelona: Herder.

Hochschild, A. R. (1975). The Sociology of Feeling and Emotion: selected possibilities. Sociological Inquiry, 45, pp. 280-307.

Hochschild, A. R. (1997). The Time Bind. When Work Becomes Home and Home Becomes Work. New York: Metropolitan books.

Hochschild, A. R. (2003). The Managed Heart. Commercialization of Human Feeling. California: University of California Press.

Hochschild, A. R. (2008). La mercantilización de la vida íntima. Apuntes de la casa y el trabajo. Barcelona: Katz. da, todos los años se añaden en ella algunos dientes traicioneros. Cuando el compañero de tu vida desaparece, tú no tienes una llave de recambio para reemplazar a esa criatura perfectamente pulida y limada que ha vivido a tu lado durante veinte o cuarenta años y que ha sido capaz de abrir tu puerta. Una llave perdida de esas características no puede volver a forjarse, solo es signo de una ausencia. Para mucha gente mayor la soledad es la consecuencia inevitable de sucesos biográficos irreversiblemente individualizantes" (2003, p. 49).

Illouz, E. (2007). Intimidades congeladas. Las emociones en el capitalismo. Barcelona: Katz.

Illouz, E. (2009). El consumo de la utopía romántica. El amor y las contradicciones culturales del capitalismo. Madrid: Katz.

Illouz, E. (2012). ¿'Por qué duele el amor? Una explicación sociológica. Barcelona: Katz.

Irigaray, L. (1990). Über die Notwendigkeit geschlechtsdifferenzierter Rechte. En: Gerhard, U. y Jansen, M. (eds.). Differenz und Gleichheit: Menschenrechte haben (k)ein Geschlecht. Frankfurt: U. Heimar Verlag.

Lipovetsky, G. (1983). L'ére du vide. Paris: Gallimard.

Mestrovic, S. (1997). Postemotional society. London: Sage Publications.

Nussbaum, M. (2008). Paisajes del pensamiento. Barcelona: Paidós.

Pinker, S. (2009). La paradoja sexual. De mujeres, hombres y la verdadera frontera del género. Barcelona: Paidós.

Precht, R. D. (2012). El amor. Un sentimiento desordenado. Madrid: Siruela.

Sennet, R. (2000). La corrosión del carácter. Las consecuencias personales del trabajo en el nuevo capitalismo. Barcelona: Anagrama.

Simmel, G. (1938). Cultura femenina y otros ensayos. Argentina: Espasa-Calpe.

Simmel, G (2003). Filosofía del dinero. Granada: Comares.

Sloterdijk, P. (2003). Experimentos con uno mismo. Valencia: Pretextos.

Zizek, S. (2011). En defensa de causas perdidas. Madrid: Akal. 